\title{
Effective Selection Criteria for Screening Drought Tolerant and High Yielding Bread Wheat Genotypes
}

\author{
Sahar Bennani ${ }^{1,2, *}$, Nasserlehaq Nsarellah ${ }^{1}$, Ahmed Birouk ${ }^{2}$, Hassan Ouabbou ${ }^{1}$, Wuletaw Tadesse ${ }^{3}$ \\ ${ }^{1}$ Department of Plant Breeding and Genetic Resources Conservation, National Institute of Agricultural Research, Morocco \\ ${ }^{2}$ Agronomy and Veterinary Hassan II Institute, Morocco \\ ${ }^{3}$ Biodiversity and Integrated Gene Management Program, International Center for Agricultural Research in the Dry Areas, Morocco
}

Copyright $(2016$ by authors, all rights reserved. Authors agree that this article remains permanently open access under the terms of the Creative Commons Attribution License 4.0 International License

\begin{abstract}
Bread wheat is the major staple food in Morocco. Drought is the most important abiotic stress decreasing yield. Breeding for drought tolerance may be improved by various plant traits. In order to investigate the best selection criteria to develop drought tolerant varieties, 40 bread wheat genotypes were evaluated under two locations representing the stressed and non-stressed environments, using randomized complete block design with three replications during the cropping season 2014. Under stressed conditions, analysis of variance exhibited significant differences among grain yield, thousand kernel weight, number of plants, number of spikes and tillers per plant, plant height, plant vigor, chlorophyll content and canopy temperature; and non-significant differences for biomass, harvest index, number of days to heading and flowering, and chlorophyll fluorescence. According to correlation and principal component analysis, the grain yield was positively related with biomass, thousand grain weight, number of fertile spikes and plant vigor; and indirectly associated positively with harvest index, plant height and negatively with number of days to flowering, canopy temperature and chlorophyll content. Those traits, correlated to grain yield under stress, can be used as indirect selection for drought tolerance to obtain higher yield potential in dryland conditions. Moreover, thousand grain weight in non-stressed conditions was positively correlated to biomass, number of fertile spikes and its homologue in stressed conditions. Also, the biomass in favorable conditions was correlated to thousand grain weight and harvest index in mild stressed conditions. Thus, those two traits may be used to improve performance in drought prone environments.
\end{abstract}

Keywords Bread Wheat, Drought Tolerance, Selection Criteria, Agro-morphologic, Physiological

\section{Introduction}

Bread wheat (Triticum aestivum L.) is one of the most important mainstay crops for food security over the world, including Morocco. In order to cope with 8.5 billion expected world population growth by 2030 , the average world wheat productivity should reach $4.3 \mathrm{t} / \mathrm{ha}$, representing $1.6 \%$ of yield increase on annual basis $[1,2]$.

Drought is a common feature of Mediterranean climate, causing large inter annual fluctuations in rainfed wheat productions, especially in dry lands areas such as Morocco. The development of new high yielding varieties tolerant to drought stress is one of the most efficient strategies to improve yields in unpredictable drylands environments. However, breeding for drought resistance is complicated by the complexity of the wheat genome and the lack of fast, reproducible drought screening techniques due to the involvement of many physiological and morphological characters [3-5]. Currently, efforts are directed to access new and cheap reliable indices that can help in selection of drought tolerant genotypes.

In general, breeding for drought tolerance involves combining good yield potential in optimum conditions and the selection of high heritable traits related to drought tolerance. Yield is the principal selection index used under drought stress conditions. However, the yield is a complex polygenic trait which QTLs are located differently from those controlling drought [6,7]. Thus, the selection efficiency could be improved if particular physiological and/or morphological attributes related to yield under a stress environment could be identified as selection criteria for complementing conventional breeding [8]. Genetic improvement of crops for drought tolerance requires a search for possible relationship between agronomic, morphologic and physiological traits and grain yield $[9,10]$. These traits should be highly heritable, greatly correlated with stress tolerance and can be easily assessed [5].

For this purpose, correlations and principal components analysis are used by researchers to distinguish significant relationships between traits. The correlation coefficient measures the mutual association between a pair of variables independent of the other variables. The principal 
components analysis is a multivariate analysis method that aims to explain the correlation between a set of variables in terms of small number of underlying independent factors $[11,12]$.

The objective of this study was to determine and identify effective agro-morphological and physiological traits for screening drought tolerance in bread wheat.

\section{Materials and Methods}

\subsection{Genetic Material and Layout of Experiments}

Fourteen bread wheat genotypes of diverse characters and origins were chosen based on their reputed differences in yield performance under irrigated and non-irrigated conditions. The trials were conducted during 2014 at two experimental fields of the National Institute of Agricultural Research in Morocco: Taoujtate representing the favorable conditions and Sidi El Aidi for stressed conditions.

The experiment was laid out in randomized complete block design (RCBD) with three replications. Each plot is composed of 6 rows of $5 \mathrm{~m}$; with row to row distance of $0.3 \mathrm{~m}$.

\subsection{Characteristics of Experimental Sites and Growing Season Pattern}

The experimental site of Taoujdate is located in the Sais region. It represents the favorable or non-stressed conditions in Morocco. The long term average rainfall is about $500 \mathrm{~mm}$ with a deep clayey soil (Tirs). During the 2013-2014 growing season, the total amount of precipitations was 277.5 $\mathrm{mm}$ /year. Additional irrigation (about $100 \mathrm{~mm}$ ) was applied during critical growing stages.

The experimental site of Sidi El Aidi belongs to Settat province located in the south of Morocco and represents the semi-arid region of Morocco. The average rainfall is about $300 \mathrm{~mm} /$ year with limestone- clay texture soil. The total amount of precipitations during the studied season was $181 \mathrm{~mm}$.

The sowing was operated during the second half of November (13th and 27th respectively for stressed and non-stressed environments). The herbicides and fungicides were applied in both environments to limit the foliar diseases and weeds development, thus restraining the confounding effects with drought stress.

The nitrogen and phosphor fertilizers (18-46-00) were applied prior to sowing at a rate of 1.5 quintal/hectare; and additional side dressing of nitrogen $(33.5 \%)$ was applied at jointing stage.

\subsection{Data Collected}

Agronomic data, such as biomass (BY) (g), number of plants (NP), number of fertile spikes (NFS) and tillers per plant (NT), plant height $(\mathrm{PH})$, thousand grain weight (TGW) (g) were evaluated based on 1 meter in each plot.

Plant height $(\mathrm{PH})(\mathrm{cm})$ was measured from soil surface to the awns of the spike at maturity stage.

Harvest index \% (HI) was calculated as the ratio of seed yield divided to total dry matter $\mathrm{x} 100$.

Finally, the grain yield (GY) (t/ha) was measured by harvesting each plot at crop maturity.

The plant early vigor (PV) was assessed using visual scale from 1 to 5 , where $1=$ low growth rate and $5=$ very vigorous growth. This parameter was assessed three times during the vegetative stage of plants with approximately 10 days of interval.

The phenological observations number of days to heading (NDH) and flowering (NDF) were calculated based on number of days from sowing to heading and flowering respectively. The dates of heading or flowering for each genotype were recorded when $50 \%$ of the ears were at this stage.

The canopy temperature $(\mathrm{CT})\left({ }^{\circ} \mathrm{C}\right)$ was evaluated using the infrared thermometer IR 1000. The reading includes the average of leaf temperature of 1 linear meter in each plot.

The chlorophyll fluorescence (CF) was evaluated using the fluorimeter Handy PEA 2307. The average of two readings was reported in each plot. The parameter calculated $(\mathrm{Fv} / \mathrm{Fm})$ is the ratio of variable fluorescence $(\mathrm{Fv})$ over the maximum fluorescence value (Fm).

The chlorophyll content (CC) was assessed using the SPAD 502 chlorophyll meter. The average of three SPAD readings was reported in each plot. This parameter was evaluated only under stressed conditions.

All the physiological traits were scored twice during this cycle. The first reading corresponded to heading stage, whereas, the second reading referred to the late flowering stage based on the intensity of drought.

Data were analyzed using GENSTAT software (3th free edition) for analysis of variance and Pearson correlations. The XLSTAT was used for the Principal Components Analysis. The statistical model used for the analysis of variance was: $\mathrm{Y}=$ Site + Block (Site) + Genotype + Genotype $\mathrm{x}$ Site + Genotype $\mathrm{x}$ Block + Error.

\section{Results}

\subsection{Grain Yield and Yield Related Traits}

The results of analysis of variance for grain yield indicated the presence of a considerable genotypic variation under non-stressed and stressed conditions (Table 1\&2). The mean yield under favorable conditions is about $3.3 \mathrm{t} /$ ha compared to $1.9 \mathrm{t} / \mathrm{ha}$ in stressed conditions. The drought stress significantly reduced the yield by $42 \%$ (Table 1 ).

Under non-stressed conditions, significant differences were observed among genotypes for all yield traits recorded, with the exception of biomass, number of plants and number of fertile spikes and tillers per plant. In the drought stressed site, significant differences were observed $(p \leq 0.05)$ for the 
biomass, harvest index, number of days to heading and flowering (Table 1).

The drought stress reduced biomass significantly by $23 \%$. The mean biomass under favorable conditions was about $271 \mathrm{~g} / \mathrm{m}$ compared to $208 \mathrm{~g} / \mathrm{m}$ in stressed conditions. The TGW was reduced only by $4 \%$ approximately. The mean HI under favorable conditions was $36.13 \%$ compared to $31.46 \%$ under stressed conditions. The reduction caused by drought was about $13 \%$.

Regarding the number of plants, this parameter showed non- significant reduction between the two treatments. However, the number of tillers and fertile spikes per plant were reduced significantly by $34.6 \%$ and $52 \%$ respectively.

\subsection{Morphological and Physiological Traits}

Under non- stressed conditions, the analysis of variance exhibited significant differences among genotypes for plant height, number of days to heading and flowering and the first reading of the chlorophyll fluorescence. However, in drought stressed environment, significant differences were observed for all the traits except for the phenological data, the first reading of the chlorophyll fluorescence and the second reading of canopy temperature.(Table 1)

Regarding the phenological data, the number of days to heading decreased from 132 days in favorable conditions to 113 days in stressed environment, meaning 9\% of reduction.

Similarly, the number of days to flowering was shortened from 135 days in favorable conditions to 123 days in stressed environment, thus reduced by $15 \%$.

The plant height was reduced by $34 \%$. The mean height in favorable conditions is $110 \mathrm{~cm}$, while it reached only $73 \mathrm{~cm}$ in stressed conditions. Contrariwise, the plant vigor was not significantly reduced, even if the genotypes performed differently under stress conditions compared to the non-stressed one.

For the first reading of chlorophyll fluorescence, the $\mathrm{Fv} / \mathrm{Fm}$ ratio means varied from 0.77 in the non-stressed conditions to 0.72 in stressed conditions, thus $7 \%$ only of reduction. However, in the second reading, it dropped to 0.67 in stressed conditions, meaning a reduction of $13 \%$.

For the chlorophyll content, the measurements were only applied at the stressed environment. The CC means were 37.09 and 39.57 for the first and second measurements, respectively.

During the first reading, the canopy temperatures was reduced by $8 \%$ with $21.08^{\circ} \mathrm{C}$ as an average for the non-stressed environment and $19.33^{\circ} \mathrm{C}$ in stressed conditions. However, in the second reading, the $\mathrm{CT}$ increased in stressed conditions $\left(19.23^{\circ} \mathrm{C}\right)$ compared to non-stressed environment $\left(15.31^{\circ} \mathrm{C}\right)$ by $26 \%$.

\subsection{Combined Analysis of Variance}

The combined analysis of variance (Table 2) over both conditions revealed significant differences among genotypes for agronomic parameters: grain yield, grain weight, number of plants, number of fertile spikes per plant, and thousand grain weights; and for the morpho- physiological traits, plant height, chlorophyll fluorescence and canopy temperatures. The site had significant impact on differences for all traits except number of plants and plant vigor.

The site $\mathrm{x}$ genotype interactions was significant only for the number of days to flowering, plant height, plant vigor, chlorophyll fluorescence and canopy temperature.

\subsection{Correlation among Yield Related Traits}

In favorable conditions, the grain yield had significant positive correlation with the number of plants $(\mathrm{r}=0.36)$, the biomass $(r=0.45)$ and the harvest index $(r=0.516)$. The number of fertile spikes per plant was positively significantly correlated with the biomass $(\mathrm{r}=0.53)$ and tillers number per plant $(r=0.634)$, while it had negative correlation with the number of plants per linear meter $(r=-0.33)$. The thousand grain weight was also positively correlated with the plant number per meter $(r=0.384)$ but negatively correlated with the tillers number per plant $(\mathrm{r}=-0.43)$.

In drought stress conditions, the grain yield had significant positive correlation with the biomass $(\mathrm{r}=0.55)$, thousand grain weight $(\mathrm{r}=0.43)$ and number of fertile spikes per plant $(\mathrm{r}=0.5)$, and these traits showed positive correlation between them. However, the grain yield didn't displayed significant correlation with the harvest index even if it is positively correlated to the two latter parameters $(r=0.50$ and 0.54 respectively). The number of fertile spikes is negatively correlated with plants number per meter $(r=-0.48)$.

The grain yield and its components under favorable conditions was not correlated with their homologues in stressed conditions, except for TGW $(r=0.63)$. Moreover, the TGW in non-stressed conditions was positively correlated with the biomass $(r=0.37)$, number of fertile spikes $(r=0.41)$ and negatively correlated with the plants number $(r=-0.34)$ under stressed conditions. Also, the biomass in favorable conditions had significant positive correlation with TGW $(r=0.33)$ and $\mathrm{HI}(\mathrm{r}=0.34)$ in stress conditions.

\subsection{Correlations among Phenological and Morphological Traits}

No correlations were found among morphological traits in favorable conditions. On the other hand, the number of days to flowering is positively correlated to number of days to heading $(\mathrm{r}=0.40)$ and negatively correlated to plant height $(r=-0.45)$ and plant vigor $(r=-0.45)$ in stressed conditions. The latter parameter was positively correlated to the plant height $(\mathrm{r}=0.56)$.

Moreover, the number of days to heading and plant height in favorable conditions were positively correlated to their homologues in stressed conditions $(r=0.34, r=0.48$ respectively), except for plant vigor $(r=-0.36)$.

\subsection{Correlations among Physiological Traits}

No correlations found between physiological traits except 
between the two readings of canopy temperatures in stressed conditions $(r=0.72)$.

\subsection{Correlations among All Traits}

In non-stressed environment, the grain yield and the harvest index were negatively correlated to number of days to heading in favorable $(r=-0.36$ and $r=-0.42$ respectively) and stressed conditions $(r=-0.40$ and $r=-0.39$ respectively). The biomass was positively correlated with the second reading of chlorophyll fluorescence $(\mathrm{r}=0.36)$.

In stressed environment, the grain yield was positively correlated with plant vigor $(\mathrm{r}=0.62)$ and negatively correlated with the number of days to flowering $(r=-0.33)$. The biomass was positively correlated with plant vigor $(r=0.574)$ and plant height in stressed $(r=0.52)$ and non-stressed conditions $(\mathrm{r}=0.47)$. The number of fertile spikes per plant was positively correlated with plant vigor and plant height $(\mathrm{r}=0.57, \mathrm{r}=0.52$ respectively). The plant height was positively correlated with plant vigor $(r=0.561)$ and TGW $(r=0.39)$. The first reading of chlorophyll content was negatively correlated with tillers number per plant $(r=-0.37)$; while the second reading is negatively correlated with TGW $(r=-0.35)$, plant vigor $(r=0.52)$ and plant height $(r=-0.42)$. The canopy temperature of both readings were negatively correlated with TGW $(r=-0.45$ and $r=-0.39$ respectively) and harvest index $(r=0.32$ and $r=-0.40$ respectively). The first reading of canopy temperature was also negatively correlated with plant vigor $(r=-0.34)$ and positively correlated to the plant number $(\mathrm{r}=0.43)$.

The grain yield in stressed conditions is negatively correlated with plant vigor in favorable conditions $(r=-0.35)$.
The number of plants was negatively correlated to plant height in non- stressed conditions $(r=-0.34)$.

The number of tillers in favorable conditions was negatively correlated with plant vigor in stressed conditions $(\mathrm{r}=-0.34)$.

The plant height in stressed conditions was positively correlated with TGW and plant height in favorable conditions ( $\mathrm{r}=0.32 ; \mathrm{r}=0.48$ respectively). The plant vigor in favorable conditions was negatively correlated with TGW in stressed conditions.

The canopy temperature of both reading in stressed conditions were negatively correlated to TGW in favorable conditions ( $r=-0.49$ and $r=-0.37$ respectively).

\subsection{Principal Component Analysis}

The Principal Components analysis explained $51 \%$ of the total variation considering the first five PCs. The PC1 explained about $17.42 \%$ of the total variation showing correlations mainly with traits under stressed conditions.

The PC1 had positive correlation with grain yield, thousand grain weight, number of fertile spikes, biomass, harvest index, plant height, plant vigor; and negative correlation with number of plants, number of days to flowering, canopy temperature, and chlorophyll content under stressed conditions. For non-stressed parameters, the first component had positive correlation with plant height, number of days to flowering, number of plants, thousand grain weight and the second reading of canopy temperature; and negative correlation with plant vigor, tillers number and the first reading of chlorophyll fluorescence.

Table 1. Analysis of genotypic variance for all traits per site

\begin{tabular}{|c|c|c|c|c|c|c|}
\hline \multirow{2}{*}{ Trait } & \multicolumn{3}{|c|}{ Non - Stressed } & \multicolumn{3}{c|}{ Stressed } \\
\cline { 2 - 7 } & Mean Square & F pr. & Mean & Mean Square & F pr. & Mean \\
\hline BY & 3092 & 0.543 & 270.9 & 3880 & 0.503 & 207.8 \\
\hline GY & 0.7476 & 0.003 & 3.311 & 0.6102 & 0.026 & 1.908 \\
\hline HGW & 47.48 & 0.007 & 36.13 & 128.8 & 0.285 & 31.46 \\
\hline NP & 29.167 & $<0.001$ & 30.1 & 1.1263 & $<0.001$ & 29 \\
\hline NFS/P & 41.34 & 0.517 & 37.02 & 113.16 & 0.015 & 57.54 \\
\hline NT/P & 0.5244 & 0.086 & 3.035 & 0.2333 & 0.016 & 1.459 \\
\hline NDF & 1.15 & 0.352 & 4.596 & 0.2574 & $<0.001$ & 3.006 \\
\hline NDH & 16.55 & 0.043 & 135.12 & 16.03 & 0.165 & 122.94 \\
\hline PH & 19.101 & $<0.001$ & 131.82 & 34.43 & 0.816 & 112.66 \\
\hline PV & 137.32 & $<0.001$ & 110.42 & 142.79 & 0.009 & 72.82 \\
\hline CF1 & 1.706 & 0.407 & 5.11 & 1.1263 & 0.008 & 5.333 \\
\hline CF2 & 0.00108 & 0.002 & 0.7751 & 0.04206 & 0.147 & 0.724 \\
\hline CCS1 & 0.0058 & 0.474 & 0.7697 & 0.11791 & 0.028 & 0.67 \\
\hline CCS2 & & & & 14.956 & $<0.001$ & 37.09 \\
\hline CT1 & 2.555 & 0.213 & 21.083 & 16.562 & 0.004 & 39.57 \\
\hline CT2 & 2.081 & 0.66 & 15.31 & 3.87 & 0.001 & 19.33 \\
\hline & & & & 0.063 & 19.23 \\
\hline
\end{tabular}


Table 2. Combined Analysis of Variance for all the traits studied

\begin{tabular}{|c|c|c|c|c|c|c|}
\hline \multirow{2}{*}{ Trait } & \multicolumn{2}{|c|}{ Genotype } & \multicolumn{2}{c|}{ Site } & \multicolumn{2}{c|}{ Interaction } \\
\cline { 2 - 7 } & MS & F pr. & MS & F pr. & MS & F pr. \\
\hline Biomass & 3532 & 0.71 & 241293 & $<0.001$ & 3645 & 0.668 \\
\hline Grain Yield & 0.8736 & $<0.001$ & 118.53 & $<0.001$ & 0.4893 & 0.159 \\
\hline Harvest Index & 90.73 & 0.181 & 1327.8 & $<0.001$ & 87.57 & 0.246 \\
\hline Thousand Grain Weight & 50.66 & $<0.001$ & 74.39 & 0.016 & 11.09 & 0.658 \\
\hline Number of plants & 86.34 & $<0.001$ & 25429 & 0.097 & 71.26 & 0.304 \\
\hline Number of Fertile Spikes/Plant & 0.4182 & 0.021 & 148.54 & $<0.001$ & 0.3405 & 0.121 \\
\hline Number of Tillers/Plant & 0.7294 & 0.135 & 151.56 & $<0.001$ & 0.6775 & 0.212 \\
\hline Number of Days to Flowering & 12.53 & 0.343 & 8914.9 & $<0.001$ & 20.18 & 0.007 \\
\hline Number of days to Heading & 35.46 & 0.062 & 22013 & $<0.001$ & 18.09 & 0.868 \\
\hline Plant Height & 202.32 & $<0.001$ & 84708 & $<0.001$ & 78.28 & 0.048 \\
\hline Plant Vigor & 0.881 & 0.818 & 2.752 & 0.121 & 1.957 & 0.01 \\
\hline Chlorophyll Fluorescence1 & 0.022 & 0.001 & 0.126 & $<0.001$ & 0.02106 & 0.002 \\
\hline Chlorophyll Fluorescence 2 & 0.0594 & $<0.001$ & 0.6395 & $<0.001$ & 0.06433 & $<0.001$ \\
\hline Canopy Temperature1 & 4.073 & 0.001 & 130.5 & $<0.001$ & 4.809 & $<0.001$ \\
\hline Canopy Temperature 2 & 3.301 & $<0.001$ & 1364.8 & $<0.001$ & 5.463 & $<0.001$ \\
\hline
\end{tabular}

*MS Mean Square

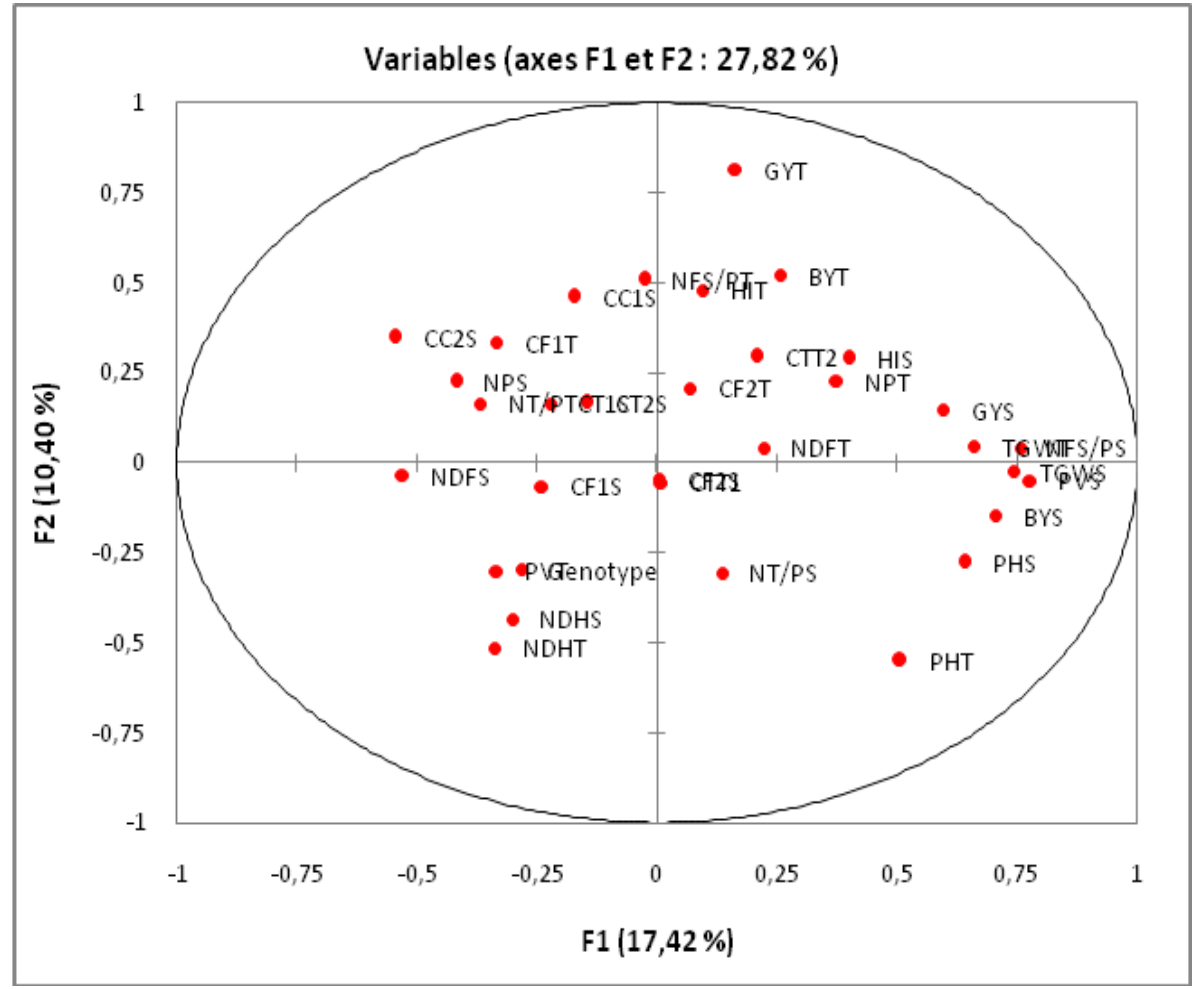

Figure 1. The biplot graphical display of the Principal Components Analysis of the traits measured in both conditions

The second component explained about $10.4 \%$ of variation. It is more related to the non-stressed conditions representing positive correlation with grain yield, number of fertile spikes, biomass, harvest index, chlorophyll fluorescence and the second lecture of canopy temperature; and negative correlation with plant vigor, plant height and number of days to heading. The other three components accounted for 9,8 and $6.6 \%$ of variation between traits respectively. The PC3 were positively related to the first measurement of chlorophyll fluorescence and content and negatively correlated to canopy temperature in stressed conditions. The PC4 and PC5 were more related to non-stressed conditions. The PC4 had positive correlation with the first reading of canopy temperature and negative one with the second lecture; while PC5 is positively correlated to tillers and fertile spikes number, and negatively correlated to plant number.

\section{Discussion}


In order to evaluate the effectiveness and reliability of a set of agro-morphological and physiological traits for screening drought tolerant genotypes, this study was conducted under stressed and non-stressed field conditions during 2014 growing season.

In the stressed conditions, the growing season was characterized by a mid and late drought, affecting differently the heading, flowering and maturity stages of the genotypes. In wheat, yield is greatly reduced mostly when drought stress occurs during the heading or flowering and soft dough stages $[13,14]$.

From the combined analysis, the significant variation due to genotypes for almost all the characters suggested that the variability among genotypes was sufficient to provide some scope for selecting traits of drought tolerance in bread wheat.

From the combined analysis, the significant variation due to genotypes for almost all the characters suggested that the variability among genotypes was sufficient to provide some scope for selecting traits of drought tolerance in bread wheat.

The non-significant interaction between site and genotypes for almost all traits revealed that cultivars presented similar ranking under both moisture conditions and that all were affected by the stress treatment which suggested that drought tolerant cultivars could reliably be selected. However, significant interactions were found for number of days to flowering, plant height, plant vigor, chlorophyll fluorescence and canopy temperature; indicating that cultivars performed differently over the stress conditions for those traits.

The grain yield is the most important component in any breeding program. However, grain yield is a complex trait that reflects the interaction of numerous components and yield related traits. Those parameters occur under different growth and development processes throughout the life cycle [15]. It is determined by several physiological, biochemical and metabolic plant processes and its genetics and associations are greatly ambiguous [16]. The comprehension of the relationships between those parameters may lead to identify the criteria that can influence the final yield under different environments. Thus, the breeders can use them as indirect selection criteria to increase the yielding capacity of bread wheat.

In this study, the grain yield under favorable conditions was about 1.6 times the yield under stress. Thus, the water stress had a great impact on the yield potential of genotypes.

The drought affected the grain yield and its components differentially among the genotypes. The number of fertile spikes was the most affected ( $52 \%$ of reduction) followed by grain yield (42\%), number of tillers $(34 \%)$, biomass $(23 \%)$, harvest index (13\%) and thousand grains weight (4\%).

Moreover, the genotypes behaved differently in the presence of stress conditions. The genotypic variation for number of plants, tillers and fertile spikes per plant was observed only under stressed conditions.

According to the results of correlation coefficients, the grain yield had a high correlation with thousand grain weight, biomass and number of fertile spikes under stressed conditions. The two former parameters had positive correlation with the harvest index. Thus, in order to increase grain yield under dryland condition, the focus should be emphasized on parameters which should be used in selection for drought tolerance breeding programs. Moreover, the trait "thousand grain weight" under favorable conditions was correlated with its homologue in stressed conditions, suggesting that high potential TGW under optimal conditions can improve yield under stress conditions. The TGW in non-stressed conditions was positively correlated with the biomass, number of fertile spikes under stressed conditions; whereas, the biomass in favorable conditions had significant positive correlation with TGW and $\mathrm{HI}$ in stress conditions. Thus, indirect selection in a drought prone environment based on the results found in optimum conditions can be efficient.

Those findings are in accordance with some previous studies that indicated the positive correlation between grain yield and yield component traits in wheat such as harvest index [17,18], number of spike per square meter [18-20] and thousand grain weight $[18,20-24]$. Taheri et al. [25] indicated a positive and significant correlation between stress tolerance index with grain yield, biomass and harvest index under normal conditions. Numerous studies deduced a positive and significant genetic correlation of wheat biomass and yields under the both moisture conditions [26,28]. The increase of biomass under conditions of drought is essential as the translocation of assimilates from vegetative parts into grain significantly contributes to yield [9, 29-31].

Regarding morphologic traits, the genotypes had more homogeneous path regarding number of days to heading and flowering under stress in comparison with non-stressed conditions. This indicated that genotypes have shortened their plant growing cycle (by reducing the number of days to heading and flowering) as a mechanism to escape from drought stress. In stressed conditions, the number of days to flowering was positively correlated to number of days to heading, and negatively correlated to the plant height and vigor. It means that when the genotype shortened its cycle and had early maturity (expressed by the increase in the number of days to flowering), it had positive effect on its growth establishment through avoidance of drought during pollination and grain filling. The correlation analysis confirmed also that the grain yield was negatively correlated to the number of days to flowering under stress conditions; while no correlation was found under favorable environment. Those findings are in agreement with previous studies [26, 32--33].

Plant height was the most influenced by drought stress (34\% of reduction) and affected the genotypes differently. Plant height had a significant indirect effect on grain yield via positive correlation with biomass, fertile spikes, plant vigor and thousand grain weights in stressed conditions. Many studies have selected plant height under dryland condition as one of the reliable morphologic trait for selecting drought tolerant genotypes to obtain a high yield potential in dryland condition s [22, 24, 34]. 
Plant vigor showed genotypic variation only under drought stress, thus illustrating the diversity among genotypes. Under stressed conditions, this parameter is positively correlated to grain yield, number of fertile spikes, biomass, plant height and thousand grain weights. The [31, $33,35]$ studies showed that grain yields of wheat were linearly related to early vigor. The early vigor was associated with greater leaf area and ground cover and probably a greater proportion of total evapotranspiration used in crop transpiration rather than soil evaporation. It allows also a better competitiveness of wheat crops against weeds $[9,36]$. Kandic et al. [33] indicated that early vigor was found to be suitable for wheat breeding under different moisture regimes.

For the physiological traits, the genetic variation was important in stressed conditions, showing difference in genotypes behavior and response to drought. Canopy temperature and chlorophyll fluorescence increased when conditions became more stressed.

The surface temperature of the canopy is related to the amount of transpiration resulting in evaporative cooling. Studies have shown that canopy temperatures is correlated with many physiological factors such as stomatal conductance, transpiration rate, plant water status, water use, leaf area index and crop yield. Genotypes with cooler canopy temperatures can be used to indicate a better hydration status. Thus, this parameter assessed the capacity to extract water from deeper soil profiles and/or agronomic water use efficiency under drought conditions [37-38]. Those statements are in concordance with our finding. Canopy temperature had a significant negative correlation with thousand grain weight and harvest index under stress conditions. Many studies attested the effectiveness of the canopy temperature as selection criteria based on its correlation with grain yield in stressed environments [39-42] and the ability to extract water under drought [43].

The chlorophyll is the green photosynthetic pigment which absorbs sunlight and transfers this energy to the reaction center of the photosystems. Thus, measuring chlorophyll content indicates photosynthetic potential [44]. Many studies concluded that the chlorophyll content could be considered as a reliable indicator for drought tolerance [41-42,45-46]. In the same way, the chlorophyll content had a significant indirect effect on grain yield via thousand grain weight, plant vigor and plant height. However, in this study, this relationship was negative.

The fluorescence is an indicator of the leaf photosynthetic performance. In the literature, there are many fluorescence parameters defined, including $(\mathrm{Fv} / \mathrm{Fm})$. It is a sensitive indicator of plant photosynthetic performance, with optimal values of 0.83 independent of the plant species [47-48]. Unlike some studies $[49,50]$, no significant correlation with yield related traits were found for chlorophyll fluorescence in our study. This could be explained by the intensity of drought. Araus et al. [50] stated that the chlorophyll fluorescence changes only under extreme stress conditions and have lower heritability.
The relationships found by correlation analysis were in agreement with the principal component analysis. The first component related grain yield in stressed conditions positively with thousand grain weight, number of fertile spikes, biomass, harvest index, plant height, and plant vigor; and negatively with plant number, number of days to flowering, canopy temperature, and chlorophyll content.

\section{Conclusions}

In conclusion, the positive correlation of biomass, thousand grain weight and number of fertile spikes with grain yield confirmed that these characters are important for direct selection of high yielding under stress and non-stressed conditions. Also, plant vigor, plant height, chlorophyll content and canopy temperature could be used simultaneously as reliable indirect morphologic and physiologic selection criteria for drought tolerance and obtaining a high yield potential under dryland condition. Moreover, the thousand grain weight, biomass and harvest index may be used to improve drought prone environments based on the favorable conditions results in order to cope with variability of rainfall over years.

However, the selected characters should be assessed under additional cropping seasons in order to confirm their efficiency under different drought stress severities.

\section{REFERENCES}

[1] H. J. Braun. How Wheat Improvement Research Impacts the World. $9^{\text {th }}$ International Wheat Conference, Sydney, Australia, 20-25 September. 2015.

[2] FAO, IFAD, WFP. The State of Food Insecurity in the World 2015. Meeting the 2015 international hunger targets: taking stock of uneven progress. Rome, FAO, 2015.

[3] M. M. Ludlow, R. C. Muchow. A critical evaluation of traits for improving crop yields in water-limited environments. Adv. Agronomy. 43:107-153, 1990.

[4] P. Ramirez-Vallejo, I. D. Kelly. Traits related to drought resistance in common bean. Euphytica, 99: 127-136. 1998.

[5] S. Dencic, R. Kastori, B. Kobiljski, B. Duggan. Evaluation of grain yield and its components in wheat cultivars and landraces under near optimal and drought conditions. Euphytica 113: 43-52, 2000.

[6] J. M. Morgan. Osmoregulation and water stress in higher plants. Annals Rev. Plant Physiology. 35, 299-319, 1984.

[7] A. Blum. Improving wheat grain filling under stress by stem reserve mobilization. Euphytica 100: 77-83, 1998.

[8] E. Acevedo. Improvement of winter cereal crops in Mediterranean environments: Use of yield, morphological and physiological traits. In Acevedo, E. (eds.): Physiology-Breeding of Winter Cereals for Stressed Mediterranean Environments. Le Colloque, INRA, Paris, 55: 
273-305, 1991.

[9] S.A Quarrie, J. Stojanovic, S. Pekic. Improving drought resistance in small grained cereals: A case study, progress and prospects. Plant Growth Regulation: 29, 1-21, 1999.

[10] W. A. Jatoi, M.J. Balog, M.B. Kumbhar. Effect of water stress on physiological and yield parameters at anthesis stage in elite spring wheat cultivars. Sahad J. Agriculture: 27, 2011.

[11] T. M. M. Machado, M. Chakir, J. J. Lauvergne. Genetic distances and taxonomic trees between goats of Ceará state (Brazil) and goats of the Mediterranean region (Europe and Africa). Genet Molecular Biology 23:121-125, 2000.

[12] H. Beheshtizadeh, A. Rezaie, A. Rezaie, A. Ghandi. Principal component analysis and determination of the selection criteria in bread wheat (Triticum aestivum L.) genotypes. International Journal of Agriculture and Crop Sciences: 5 (18), 2024-2027, 2013.

[13] P. J. Stone PJ, M. E. Nicolas. A survey of the effects of high temperature during grain filling on yield and quality of 75 wheat cultivars. Australian Journal of Agricultural Research; 46: 475-492, 1995.

[14] K. Al-Khatib, G. M. Paulsen. Mode of high temperature injury to wheat during grain development. Physiologia Plantarum 61: 363-368, 1984.

[15] S. A. Quarrie, S. P. Quarrie, R. Radosevic, D. Rancic, A. Kaminska, J.D. Barnes, M. Leverington, C. Ceoloni, D. Dodig. Dissecting wheat QTL for yield present in a range of environments: from the QTL to candidate genes. Journal of Experimental Botany; 57:2627-2637, 2006.

[16] Z. Ali, S. M. A. Basra, H. Munir, A. Mahmood, S. Yousaf. Mitigation of drought stress in maize by natural and synthetic growth promoters. J. Agric. Soc. Sci. 7: 56-62, 2011.

[17] M. G. Ghaderi, H. Zeinalikhanghah, A. H. Hosseinzadeh, A. R. Taleei, M. R. Naghavi. Evaluation of relationships between grain yield, yield components and the other characteristics associated with grain yield in bread wheat using multivariate statistical analysis. Iran J crop Res 7(2):573-582, 2009

[18] A. A. Leilah, S. A. Al-Khateeb. Statistical analysis of wheat yield under drought conditions. J Arid Env 61:483-496, 2005.

[19] M. Zakizadeh, M. Esmaeilzadeh, D. Kahrizi. Study on genetic variation and relationship between plant characteristics and grain yield in long spike bread wheat (Triticum aestivum L.) genotypes-using multivariate analysis. Iran J Crop Sci 12(2):18-30, 2010.

[20] K. Shamsi, M. Petrosyan, G. Noor-Mohammadi, A. Haghparast, S. Kobraee, B. Rasekhi. Differential agronomic responses of bread wheat cultivars to drought stress in the west of Iran. African Journal of Biology 10(14):2708-271, 2011.

[21] V. Mollasadeghi, A. A. Imani, R. Shahryari, M. Khayatnezhad. Correlation and path analysis of morphological traits in different wheat genotypes under end drought stress condition. Mid-East J Sci Res 7(2):221-224, 2011.

[22] M. Mohammadi M, P. Sharafi, R. Karimizadeh, M. K. Shefazadeh. Relationships between Grain Yield and Yield Components in Bread Wheat under Different Water Availability (Dryland and Supplemental Irrigation Conditions). Not Bot Horti Agrobo, 40(1):195-200, 2012.
[23] M. Hatim M, M. Majidian. Effect of Terminal Season Water Stress on Yield, Yield Component and Remobilization in Different Cultivar and Lines of Bread Wheat. Intl. J. Agri. Crop Sci., 4(16): 1215- 1220, 2012.

[24] A. R. Koocheki, A. Yazdansepas, U. Mahmadyorov, M.R. Mehrvar. Physiological-based Selection Criteria for Terminal Drought in Wheat (Triticum aestivum L.). J. Agr. Sci. Tech. 16: 1043-1053, 2014.

[25] N. Taheri, H. Heidari, K. Yousefi, S. R. Mousavi. Effect of organic manure with phosphorus and zinc on yield of seed potato. Australian Journal of Basic and Applied Sciences, 5(8): 775-780, 2011.

[26] M. Van Ginkel, D. S. Calhoun, G. Gebeyehu. Plant traits related to yield of wheat in early, late or continuous drought conditions. Euphytica: 100, 109-121, 1998.

[27] R. Rosales-Serna, J. Kohashi-Shibata, J. A. Acosta-Gallegos, C. Trejo-Lopez, J. Ortiz-Cereceres, J. D. Kelly. Biomass distribution, maturity acceleration and yield in drought-stressed common bean cultivars. Field Crops Res. 85, 203-211, 2004.

[28] E. Acosta-Díaz, C. Trejo-López, L. Ruiz-Posadas, J. S. Padilla-Ramírez, J. A. Acosta-Gallegos. Adaptación del frijol a sequía en la etapa reproductiva. TERRA Latino-americana 22: 49-58, 2004.

[29] P.C Pheloung, K. H. M. Siddique. Contribution of stem dry matter to grain yield in wheat cultivars. Australian Journal of Plant Physiology 18: 53-64, 1991.

[30] M. Reynolds, D. Calderini, A. Condon, M. Vargas. Association of source/sink traits with yield, biomass and radiation use efficiency among random sister lines from three wheat crosses in a high-yield environment. J. Agri. Sci., 145, 3-16, 2007.

[31] B. R. Whan, G.P. Carlton, W. K. Anderson. Potential for increasing early vigor and total biomass in spring wheat. I. Identification of genetic improvements. Australian Journal of Agricultural Research: 42, 347-361, 1991

[32] N. Ud-Din, B. F. Carver, A. C. Clutter. Genetic analysis and selection for wheat yield in drought stressed and irrigated environments. Euphytica, 62, 89-96, 1992.

[33] V. Kandic, D. Dodig, M. Jovic, B. Nikolic, S. Prodanovic. The importance of physiological traits in wheat breeding under irrigation and drought stress. Genetica, Vol. 41, No. 1, 11-20, 2009.

[34] S. P. Singh. Broadening the genetic base of common bean cultivars: a review. Crop Science 41, 1659-1675, 2001.

[35] N. C. Turner, M. Nicolas. Drought resistance of wheat for light textured soils in a Mediterranean climate. In Drought Tolerance in Winter Cereals (Srivastava JP, Porceddu E, Acevedo E and VarmaS (eds.). John Wiley \& Sons, Chichester. pp. 203-216. 1987.

[36] G. J. Rebetzke, R. A. Richards. Genetic improvement of early vigour in wheat. Austral. J. Agric. Res. 50 291-302, 1999.

[37] J. L. Araus, G. A. Slafer, M. P. Reynolds MP, C. Royo. Plant breeding and drought in $\mathrm{C} 3$ cereals: What should we breed for? Annals of botany 89: 925-940, 2002. 
[38] J. Pietragalla. Canopy temperature. In : physiological breeding II: A field guide to wheat phenotyping. Pask A, Pietragalla J, Mullan D and Reynolds M (Eds.). Pp: 10-14. Mexico, CIMMYT, 2011.

[39] M. P. Reynolds, M. Balotac, M. I. B. Delgado, I. Amani, R. A. Fischer. Physiological and Morphological Traits Associated with Spring Wheat Yield under Hot, Irrigated Conditions. Aust. J. Plant Physiol.: 21,717-30. 1994.

[40] R. M. Trethowan, M. P. Reynolds. Drought resistance: Genetic approaches for improving productivity under stress. In: Buck HT, Nisi JE and Solomon N (Eds). Wheat production in stressed environments Series: Developments in plant breeding Vol.12. 2007.

[41] R. Talebi. Evaluation of Chlorophyll Content and Canopy Temperature as Indicators for Drought Tolerance in Durum Wheat (Triticum durum Desf.). Australian Journal of Basic and Applied Sciences, 5: 1457-1462. 2011.

[42] M. Abdipur, H. R. Ramezani, V. Bavei, S. Talaee. Effectiveness of canopy temperature and chlorophyll content measurements at different plant growth stages for screening of drought tolerant wheat genotypes. American-Eurasian J. Agric. \& Environ. Sci., 13 (10): 1325-1338. 2013.

[43] M. Lopes, M. P. Reynolds. Partitioning of assimilates to deeper roots is associated with cooler canopies and increased yield under drought in wheat. Functional Plant Biology 37, 147-156. 2010.
[44] De Mullan, D Mullan. Chlorophyll Content. In: physiological breeding II: A field guide to wheat phenotyping. Pask A, Pietragalla J, Mullan D and Reynolds M (Eds.). Pp: 41-43. Mexico, CIMMYT. 2012.

[45] L. Rong-hua, G Pei-guo, M. Baum, Grando S, Ceccarelli S (2006). Evaluation of chlorophyll content and fluorescence parameters as indicators of drought tolerance in barley. Agric. Sci. China 5:751-757.

[46] F. G. Arjenaki, R. Jabbari, A. Morshedi. Evaluation of drought stress on relative water content, chlorophyll content and mineral elements of wheat (Triticum aestivum L.) varieties. International Journal of Agriculture and Crop Sciences 4, 726-729. 2012.

[47] O. Bjorknan, B. Demmig. Photon yield of O2 evolution and chlorophyll flurorescence characteristics at $77 \mathrm{~K}$ among vascular plants of diverse origins. Planta: 170: 489-504. 1987.

[48] G. N. Johnson, A. J. Young, J. D. Schole, P. Horton. The dissipation of excess excitation energy in British plant species. Plant cell and Environment. 16, 673-679. 1993.

[49] Y. Jiang, B. Huang. Effects of drought or heat stress alone and in combination on kentuky Bluegrass. Crop Science 40, 1358-1362. 2000.

[50] Araus JL, Amaro T, Voltas J, Nakkhoul H and Nachit MM. Chlorophyll fluorescence as a selection criterion for grain yield in durum wheat under Mediterranean conditions. Field Crops Research 55: 209-223. 1998. 